\title{
The relationship between preoperative anxiety level, ABO blood types and birth outcomes in cesarean sections
}

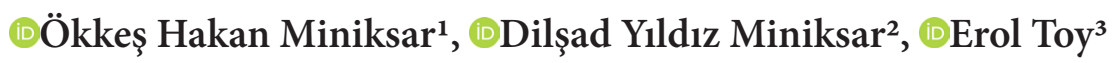 \\ ${ }^{1}$ Yozgat Bozok University, Faculty of Medicine, Department of Anesthesiology and Reanimation, Yozgat, Turkey \\ ${ }^{2}$ Yozgat Bozok University, Faculty of Medicine, Department of Child and Adolescent Psychiatry, Yozgat, Turkey \\ ${ }^{3}$ Karabük University, Karabuk University Education Research Hospital, Department of Anesthesiology and Reanimation, Karabük, Turkey
}

Cite this article as: Miniksar ÖH, Miniksar DY, Toy E. The relationship between preoperative anxiety level, ABO blood types and birth outcomes in cesarean sections. J Health Sci Med 2021; 4(6): 949-953.

\begin{abstract}
Objective: There is a relationship between $\mathrm{ABO}$ blood groups, which are part of the genetic phenotype, and various psychiatric diseases. Our primer aim in this study is to examine the relationship between $\mathrm{ABO}$ blood groups and preoperative anxiety (POA) levels in patients undergoing elective cesarean section. The secondary aim is to determine the relationship between POA levels and birth outcomes in pregnant women.

Material and Method: A total of 132 patients with different ABO blood groups who were scheduled for elective cesarean section under spinal anesthesia between August 2020 and July 2021 at the Medical Faculty Hospital were included in this prospective observational study. State Anxiety Inventory scores (SAI) were used to assess preoperative anxiety in groups A, B, $\mathrm{AB}$, and $\mathrm{O}$. Birth outcomes (fetal birth weight, birth sex and APGAR scores at the 1st and 5th minutes) were recorded.

Results: There were 55 people (41.7\%) in the A blood group, 43 people (32.6\%) in the O blood group, 25 people (18.9\%) in the B blood group, 9 people (6.8\%) in the AB blood group. A total of 73/132 (55.3\%) patients with SAI score $>40$ were identified. There was no significant difference in mean SAI scores in $\mathrm{A}, \mathrm{B}, \mathrm{AB}$ and $\mathrm{O}$ blood groups $(\mathrm{p}=0.531)$. Fetal birth weight was found to be lower in patients with high SAI scores $(\mathrm{p}=0.044)$.

Conclusion: There was no relationship between $\mathrm{ABO}$ blood groups and preoperative anxiety and birth outcomes in elective cesarean sections under spinal anesthesia, but low fetal birth weight was found in pregnant women with high anxiety. More studies with larger sample sizes in the future are needed to confirm the results of our study.
\end{abstract}

Keywords: ABO blood types, preoperative anxiety, birth outcomes, spinal anaesthesia, caesarean section

\section{INTRODUCTION}

Antenatal preoperative anxiety (POA) is a common problem that can cause negative physiological responses in pregnant women due to pain and fear of delivery. POA is more common in cesarean section, which is the most common obstetric surgery (1-4).

High-level anxiety symptoms before cesarean section cause an increase in catecholamine levels and thus may result in increased heart rate, blood pressure, and cardiac stimulation $(1,2,5)$. However, many studies have shown that maternal stress causes many negative clinical outcomes such as low birth weight and preterm delivery (5-7). For these reasons, predetermining the factors that trigger POA by clinicians can reduce these negative outcomes.

While POA level varies according to age, gender, type of operation and negative operation experience, genetic factors also affect anxiety level (8). Multifactorial factors play a role in the etiology of many psychiatric diseases. These factors are generally genetic and environmental factors. Studies examining the genetics of psychiatric diseases have shown that gene-environment interaction is determinant, especially in anxiety disorders (9). Blood group types are genetically inherited from parents and ancestors $(9,10)$. Observational studies investigating $\mathrm{ABO}$ blood types, preoperative anxiety and phenotypic factors are limited in the literature. To the best of our knowledge, a study examining $\mathrm{ABO}$ blood types and preoperative anxiety was found in the literature (11). In this study, POA levels of patients with AB blood group were found to be higher than those with other blood groups (11). 
When the literature is examined, it has been found that ABO blood groups are associated with many clinical conditions, including diabetes, various types of cancer, and cardiovascular diseases $(12,13)$. Thus, it reveals that ABO blood group types may be associated with some diseases. For these reasons, we hypothesized in this study that there is a relationship between $\mathrm{ABO}$ blood types and preoperative anxiety levels in CS deliverys, which is a stressful surgical procedure.

The main aim of current study is to evaluate the relationship between $\mathrm{POA}$ levels according to $\mathrm{ABO}$ blood groups in patients undergoing elective cesarean section. The secondary aim is to determine the relationship between POA levels and birth outcomes in pregnant women.

\section{MATERIAL AND METHOD}

\section{Study Design}

This prospective cross-sectional study was conducted at Yozgat Bozok University Faculty of Medicine Hospital (Yozgat, Turkey) between August 2020 and July 2021. The study was carried out with the permission of Yozgat Bozok University Clinical Research Ethics Committee (Date: 29.07.2020, Decision No: 2017-KAEK189_2020.07.29_07). All procedures were carried out in accordance with the ethical rules and the principles of the Declaration of Helsinki.

\section{Participants}

A total of 132 pregnant women between the ages of 1845 whose gestational age was $36-41$ weeks, who gave written informed consents and who underwent elective cesarean section with medical indications under spinal anesthesia were included in the study. The numbers of the $\mathrm{A}, \mathrm{O}, \mathrm{B}$ and $\mathrm{AB}$ blood type groups were 55, 43, 88 and 9, respectively. Patients with a known psychiatric or neurological disease, drug users, patients who did not have the mental competence to understand the survey questions or were illiterate, patients scheduled to undergo an emergency cesarean operation, urgent patients were not included in the study.

\section{Procedures}

Preoperatif anxiety levels in patients who were referred to an anesthesia outpatient clinic due to elective cesarean section were evaluated using the State Anxiety Inventory (SAI). Maternal demographic and medical data (smoking status, educational level, employment status, anesthesia history) were recorded for prenatal evaluation by anesthetists. The gestational week was calculated based on the ultrasound imaging performed during the first trimester by the obstetrics department. Following delivery, fetal birth weight, birth sex and APGAR scores at the 1st and 5th minutes were recorded. The health status of the newborns was evaluated using the 10-point APGAR score, which evaluates five parameters (heart rate, respiratory effort, muscle tone, reflex irritability and color) with a score from 0 to 2 . A total score of 7 or higher suggests that the newborn is in good health, while a total score of 4 to 6 means the newborn needs medical attention, and scores of 3 or lower indicate a critical condition (14).

\section{Preoperative anxiety assessment}

The SAI scale (20 items) determines how the individual feels at a certain time and under certain conditions. The SAI scale is scored between 20 and 80 points, where higher scores indicate a higher level of anxiety. The SAI is widely used to assess anxiety in pregnancy, and their validity and reliability have been demonstrated (1). In the evaluation of the scale score, 40 points was considered the threshold value, as is common in the literature (1), scores below 40 were classified as 'low to moderate' anxiety, and scores above 40 were classified as 'high' anxiety.

\section{Statistical Analysis}

Data were analyzed using SPSS v.20.0 (SPSS Inc., Chicago, IL, USA) software. Data were expressed as mean \pm standard deviation. The normality of distribution was checked using the Kolmogorov-Smirnov test and histograms. Normally distributed continuous variables are reported as mean \pm standard deviation (SD), non-normally distributed variables as median [interquartile range], and categorical variables as counts (\%). Differences in nonnormally distributed variables between two independent groups were assessed using the non-parametric MannWhitney U-test. A one-way ANOVA, chi-square test, or Kruskal-Wallis pairwise comparisons were used to identify the difference among the $\mathrm{A}, \mathrm{B}, \mathrm{AB}$, and $\mathrm{O}$ blood type groups in some variables. All comparative analyzes were 2 -tailed, and a P-value of less than 0.05 was considered to be statistically significant.

\section{RESULTS}

Of the 132 female patients included in the study, $41.7 \%$ $(n=55)$ A, 32.6\% $(n=43)$ O, 18.9\% $(n=25) B$, and $6.8 \%$ $(n=9) A B$ were patients with blood group. The mean age of blood groups $\mathrm{A}, \mathrm{B}, \mathrm{AB}$ and $\mathrm{O}$ was $28.8 \pm 6.0,31.6 \pm 5.8$, $31.5 \pm 7.3$ and $29.3 \pm 5.9$, respectively. Blood groups did not differ significantly according to sociodemographic (age, gravity, parity, gestational age, smoking status, education level, employment status, anesthesia history) and clinical characteristics. Fetal birth weight was similar between groups $(\mathrm{p}=0.456)$. There was no difference between ABO blood groups according to birth sex $(p=0.230)$. The 1 st min and 5th min APGAR scores were similar between the groups (0.747, 0.539, respectively) (Table 1 ). 


\begin{tabular}{|c|c|c|c|c|c|c|c|}
\hline \multicolumn{2}{|l|}{ Variables } & $A(n=55)$ & B $(n=25)$ & $\mathrm{AB}(\mathrm{n}=9)$ & $O(n=43)$ & Total $(n=132)$ & P value \\
\hline \multicolumn{2}{|l|}{ Age (years) } & $28.8 \pm 6.0$ & $31.6 \pm 5.8$ & $31.5 \pm 7.3$ & $29.3 \pm 5.9$ & $29.7 \pm 6.0$ & $0.198^{\mathrm{a}}$ \\
\hline \multicolumn{2}{|l|}{ Gravity } & $2[2$ to 3$]$ & $3[2$ to 4$]$ & $3[2$ to 4$]$ & $3[2$ to 4$]$ & $3[2$ to 4$]$ & $0.296^{\mathrm{b}}$ \\
\hline \multicolumn{2}{|l|}{ Parity } & $1[1$ to 2$]$ & $2[1$ to 2$]$ & $2[1$ to 2$]$ & $2[1$ to 3$]$ & $1[1$ to 2$]$ & $0.280^{\mathrm{b}}$ \\
\hline \multicolumn{2}{|c|}{ Gestational age (weeks) } & 38 [38 to 39$]$ & 38 [38 to 39$]$ & 38 [38 to 39$]$ & 38 [38 to 39$]$ & 38 [38 to 39$]$ & $0.992^{\mathrm{b}}$ \\
\hline \multicolumn{2}{|c|}{ APGAR score $1^{\text {st }} \min$} & 8 [8 to 9$]$ & $8[7$ to 9$]$ & $8[7$ to 9$]$ & $9[7$ to 9$]$ & $8[8$ to 9$]$ & $0.747^{\mathrm{b}}$ \\
\hline \multicolumn{2}{|c|}{ APGAR score $5^{\text {th }} \min$} & $9[9$ to 10$]$ & $9[8$ to 10$]$ & $10[9$ to 10$]$ & $10[9$ to 10$]$ & $9[9$ to 10$]$ & $0.539^{\mathrm{b}}$ \\
\hline \multicolumn{2}{|c|}{ Fetal birth weight (grams) } & $3175 \pm 454$ & $3327 \pm 373$ & $3283 \pm 432$ & $3287 \pm 480$ & $3248 \pm 447$ & $0.456^{\mathrm{a}}$ \\
\hline \multirow{2}{*}{ Birth sex } & Male & $36(65.5)$ & $11(44)$ & $4(44.5)$ & $22(51.2)$ & $73(55.4)$ & \multirow{2}{*}{$0.230^{*}$} \\
\hline & Female & $19(34.5)$ & $14(56)$ & $5(55.5)$ & $21(48.8)$ & $59(44.6)$ & \\
\hline \multirow{2}{*}{$\begin{array}{l}\text { Smoking } \\
\text { status, n (\%) }\end{array}$} & Yes & $14(25.5)$ & $8(0.32)$ & $1(11.2)$ & $15(34.9)$ & $38(28.7)$ & \multirow{2}{*}{$0.462^{*}$} \\
\hline & No & $41(74.5)$ & $17(0.68)$ & $8(88.8)$ & $28(65.1)$ & $94(71.3)$ & \\
\hline \multirow{3}{*}{$\begin{array}{l}\text { Educational } \\
\text { level }\end{array}$} & Primary school & $20(36.3)$ & $8(32)$ & $3(33.3)$ & $18(39.5)$ & $49(36.3)$ & \multirow{3}{*}{$0.906^{\#}$} \\
\hline & Secondary school & $26(47.2)$ & $10(40)$ & $4(44.4)$ & $17(39.5)$ & $57(43.1)$ & \\
\hline & University & $9(16.3)$ & $7(28)$ & $2(22.3)$ & $8(18.6)$ & $26(19.6)$ & \\
\hline $\begin{array}{l}\text { Employment } \\
\text { status }\end{array}$ & Employed & $21(38.1)$ & $10(40)$ & $3(33.4)$ & $14(32.5)$ & $48(36.4)$ & $0.913^{*}$ \\
\hline \multirow{2}{*}{$\begin{array}{l}\text { Anesthesia } \\
\text { history }\end{array}$} & Yes & $36(65.5)$ & $16(64)$ & $5(55.5)$ & $30(69.7)$ & $87(66.0)$ & \multirow{2}{*}{$0.859^{*}$} \\
\hline & No & $19(34.5)$ & $9(36)$ & $4(44.5)$ & $13(30.3)$ & $45(34.0)$ & \\
\hline
\end{tabular}

test were used to identify the difference among the A, B, AB, and O blood type groups in some variables. ${ }^{\star}$ Chi-square Test; \#Fisher's exact test. SAI, State Anxiety Inventory.

\begin{tabular}{|c|c|c|c|c|c|c|}
\hline Variables & $A(n=55)$ & $B(n=25)$ & $\mathrm{AB}(\mathrm{n}=9)$ & $O(n=43)$ & Total $(n=132)$ & P value \\
\hline SAI score & $42.1 \pm 10.9$ & $45.4 \pm 11.9$ & $43.4 \pm 11.0$ & $41.5 \pm 10.7$ & $42.6 \pm 11.0$ & $0.531^{\mathrm{a}}$ \\
\hline Patients with SAI score $>40, \mathrm{n}(\%)$ & $31(56.4)$ & $15(60.0)$ & $5(55.6)$ & $22(51.2)$ & $73(55.3)$ & $0.921^{\#}$ \\
\hline
\end{tabular}

SAI score was used to assess preoperative anxiety in patients with blood groups $\mathrm{A}, \mathrm{B}, \mathrm{AB}$, and $\mathrm{O}$. Then, the relationship of different blood groups with SAI scores was examined. The mean SAI score of the patients was 42.6 \pm 11.0 . A total of $73 / 132(55.3 \%)$ patients with SAI score $>40$ were identified. The number of patients with high preoperative anxiety did not differ according to ABO blood groups $(p=0.921)$. There was no significant difference in mean SAI scores in $\mathrm{A}, \mathrm{B}, \mathrm{AB}$ and $\mathrm{O}$ blood groups $(\mathrm{p}=0.531)$ (Table 2$)$. The lowest SAI score was found in O blood group $(41.5 \pm 10.7)$ and the highest SAI

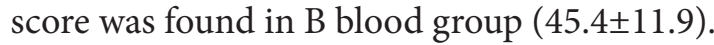

Detailed information about the differences between pregnant women with and without high anxiety is presented in Table 3 . There was no statistically significant difference between maternal age and gestational week and POA groups $(\mathrm{p}=0.367, \mathrm{p}=0.436$, respectively). Fetal birth weight was found to be lower in patients with high SAI scores $(\mathrm{p}=0.044)$ (Table 3$)$. However, there was no significant correlation between SAI scores and APGAR scores (respectively, $\mathrm{p}=0.055, \mathrm{p}=0.066$ ) (Table 3 ).

\section{DISCUSSION}

Although many studies have investigated the relationship between various psychiatric diseases and blood groups, the relationship between $\mathrm{POA}$ and $\mathrm{ABO}$ blood groups has not been studied in pregnant women with high anxiety levels who will have a cesarean delivery. The
Table 3. Characteristics of the mother and the newborn according to preoperative anxiety groups

\begin{tabular}{|lccc|}
\hline Variables & $\begin{array}{c}\text { Patients with } \\
\text { SAI score }<\mathbf{4 0}\end{array}$ & $\begin{array}{c}\text { Patients with } \\
\text { SAI score }>\text { 40 }\end{array}$ & $\begin{array}{c}\text { P } \\
\text { value }\end{array}$ \\
\hline Maternal characteristics & & & \\
Age (years) & $30 \pm 6$ & $29 \pm 6$ & $0.367^{\mathrm{a}}$ \\
Gestational age (weeks) & $38[38$ to 39] & $38[38$ to 39$]$ & $0.436^{\mathrm{b}}$ \\
Newborn characteristics & & & \\
Fetal birth weight (grams) & $3327 \pm 468$ & $3187 \pm 421$ & $0.044^{\mathrm{a}}$ \\
APGAR score $1^{\text {st }}$ & $9[8$ to 9$]$ & $8[7$ to 9$]$ & $0.055^{\mathrm{b}}$ \\
APGAR score $5^{\text {th }}$ & $10[9$ to 10$]$ & $9[9$ to 10$]$ & $0.066^{\mathrm{b}}$ \\
\hline
\end{tabular}

Values are quoted as the mean \pm SD and median [interquartile range] for continuous variables. ${ }^{\mathrm{a} I n d e p e n d e n t ~ s a m p l e ~} \mathrm{t}$ test, ${ }^{\mathrm{b}}$ Mann Whitney U test, SAI: State Anxiety Inventory.

primary aim of this prospective, observational study was that preoperative anxiety scores of pregnant women in cesarean deliveries were associated with $\mathrm{ABO}$ blood group types; The secondary aim was to test the hypothesis that POA scores affect birth outcomes. Several important findings were identified in the current study. Firstly; POA levels of pregnant women did not differ according to ABO blood group types. Secondly; Lower fetal birth weight was found in pregnant women with high POA levels. Finally; There was no significant correlation between POA levels and APGAR scores.

Many studies have shown that genetic factors such as blood group antigens are associated with the development and severity of some diseases (diabetes, cardiovascular diseases, endocrine diseases) $(12,13,15)$. It has been determined that genes controlling blood group antigen 
expression are associated with genes encoding dopamine beta-hydroxylase, catechol-O-methyl-transferase and argininosuccinate synthetase activities that regulate neuropsychiatric responses. It has even been claimed that genes encoding $\mathrm{ABO}$ blood group antigens control dopamine beta-hydroxylase activity $(15,16)$. For these reasons, the potential role of the $\mathrm{ABO}$ blood group in psychiatric diseases (schizophrenia, bipolar and unipolar depression) and personality traits, which are thought to be predominantly inherited, has been investigated in various studies, but conflicting results have been found (17-19).

When the literature was examined, in a study examining the relationship between dental anxiety and blood group in children, the highest level of dental anxiety was found in those with AB blood group (20). Similarly, Feng Xu et al. (11), preoperative anxiety levels were found to be higher in people with $\mathrm{AB}$ blood type. In another study examining blood groups and stress levels, it was found that pathological and general stress levels were found in people with the lowest O blood group (21). Similarly, in the current study, the mean SAI score was found in the lowest O blood group (41.5 \pm 10.7$)$ and the highest in B blood group (45.4 \pm 11.9$)$. However, no significant relationship was found between the POA levels of pregnant women and $\mathrm{ABO}$ blood groups. The reason for these results may be related to the effect of many variables on POA, including surgical factors other than blood groups.

In the literature, there are studies reporting a relationship between maternal $\mathrm{ABO}$ blood groups and adverse birth outcomes (most commonly preeclampsia, venous thromboembolism, chorioamnionitis, and postpartum hemorrhage) $(22,23)$. Premature birth and low birth weight are among these negative outcomes associated with blood type. In a recent study, it was reported that pregnant women with maternal B blood group had lower fetal birth weight, but there was no relationship between preeclampsia and gestational week and blood groups (22). In the same study, the authors reported that fetal growth may be adversely affected as a result of placental insufficiency due to the etiological role of blood groups in arterial thrombosis. However, in this study, the authors did not analyze other adverse pregnancy risk factors such as gestational diabetes mellitus, smoking, chorioamnionitis and venous thromboembolism (22). According to the results of our study, no significant difference was found between $\mathrm{ABO}$ blood groups and fetal birth weight, APGAR scores and gestational week. This issue, which are still controversial, need to be investigated with further studies.

Another important result in our study is that pregnant women with high POA levels have lower fetal birth weights and similar APGAR scores. POA, which is more common in cesarean deliveries, has been shown to cause many adverse birth outcomes such as premature birth, low birth weight, and low APGAR scores (5-7). It has been reported that the autonomic stress response triggered by maternal anxiety may cause negative fetal outcomes due to uterine artery vasoconstriction $(7,24)$. On the other hand, although there are studies reporting that there is no relationship between maternal anxiety and APGAR scores (25), there are also studies reporting that maternal anxiety causes low APGAR scores $(4,7)$. There is still no consensus on whether there is a true relationship between POA and adverse birth outcomes.

This study has some strengths and limitations. One of its strengths is that, to the best of our knowledge, it is the first original study in the literature to investigate the relationship between $\mathrm{AB} 0$ blood groups and preoperative anxiety in pregnant women. Other strengths are that the study is prospective and blood groups are obtained from data of the Hospital Blood Bank, not verbally. The limitations are; rare blood groups require more patients due to the small number of patients, and $\mathrm{Rh}$ sub blood groups are not included in the study.

\section{CONCLUSION}

We planned this study with the hypothesis that there may be a relationship between $\mathrm{ABO}$ blood groups, which are known to be associated with many psychiatric disorders and various personality types, and preoperative anxiety. As a result, it was determined that there was no relationship between $\mathrm{ABO}$ blood groups and preoperative anxiety and birth outcomes in cesarean section, but low fetal birth weight was found in pregnant women with high anxiety. For this reason, the identification of pregnant women with high preoperative anxiety levels and removing anxiety may contribute to the prevention of negative birth results to the fetus such as low birth weight. However, we think that our results are interesting and further studies are needed in different races and geographical regions to clarify these results.

\section{ETHICAL DECLARATIONS}

Ethics Committee Approval: The study was carried out with the permission of Yozgat Bozok University Clinical Researchs Ethics Committee (Date: 29.07.2020, Decision No: 2017-KAEK-189_2020.07.29_07).

Informed Consent: All patients signed the free and informed consent form.

Referee Evaluation Process: Externally peer-reviewed.

Conflict of Interest Statement: The authors have no conflicts of interest to declare.

Financial Disclosure: The authors declared that this study has received no financial support. 
Author Contributions: All of the authors declare that they have all participated in the design, execution, and analysis of the paper, and that they have approved the final version.

\section{REFERENCES}

1. Akildiz M, Aksoy Y, Kaydu A, Kaçar CK, Şahin ÖF, Yıldırım ZB. Effect of anaesthesia method on preoperative anxiety level in elective caesarean section surgeries. Turk J Anaesthesiol Reanim 2017; 45: 36-40

2. Badner NH, Nielson WR, Munk S, Kwiatkowska C, Gelb AW. Preoperative anxiety: detection and contributing factors. Can Anaesth 1990; 37: 444-7.

3. Sun $\mathrm{Y}$, Huang $\mathrm{K}, \mathrm{Hu} \mathrm{Y}$, et al. Pregnancy-specific anxiety and elective cesarean section in primiparas: A cohort study in China. PLoS One 2019; 14: 1-13.

4. Horsch A, Gilbert L, Lanzi S, Kang JS, Vial Y, Puder JJ. Prospective associations between maternal stress during pregnancy and fasting glucose with obstetric and neonatal outcomes. J Psychosom Res 2019; 125: 109795.

5. Van Den Bergh BRH, Mulder EJH, Mennes M, Glover V. Antenatal maternal anxiety and stress and the neurobehavioural development of the fetus and child: Links and possible mechanisms. A review. Neurosci Biobehav Rev 2005; 29: 237-58.

6. O Pimenta BS, Y Nomura RM, Nakamura MU, Moron AF Maternal anxiety and fetal movement patterns in late pregnancy. J Matern Neonatal Med 2016; 29: 2008-12.

7. Ding XX, Wu Y Le, Xu SJ, et al. Maternal anxiety during pregnancy and adverse birth outcomes: A systematic review and meta-analysis of prospective cohort studies. J Affect Disord 2014; 159: 103-10.

8. Theunissen M, Peters ML, Bruce J, Gramke HF, Marcus MA. Preoperative anxiety and catastrophizing: A systematic review and meta-analysis of the association with chronic postsurgical pain. Clin J Pain 2012; 28: 819-41.

9. Fogelman N, Canli T. Early life stress, physiology, and genetics: a review. Front Psychol 2019; 10: 1668.

10.De Gregori M, Diatchenko L, Ingelmo PM, et al. Human genetic variability contributes to postoperative morphine consumption. J Pain 2016; 17: 628-36.

11.Xu F, Yin JW, Xiong EF, et al. Correlation between preoperative anxiety and $\mathrm{ABO}$ blood types: Evidence from a clinical cross-sectional study. Dis Markers 2019; ID: 1761693 (doi: $10.1155 / 2019 / 1761693)$.

12. Franchini M, Mengoli C, Lippi G. Relationship between ABO blood group and pregnancy complications: A systematic literature analysis. Blood Transfus 2016; 14: 441-8.

13. Stakišaitis $\mathrm{D}$, Juknevičienė $\mathrm{M}$, Ulys $\mathrm{A}$, et al. $\mathrm{ABO}$ blood group polymorphism has an impact on prostate, kidney and bladder cancer in association with longevity. Oncol Lett 2018; 16: 1321-31.

14. Thorngren-Jerneck K, Herbst A. Low 5-minute Apgar score: A population-based register study of 1 million term births. Obstet Gynecol 2001; 98: 65-70.

15. Anstee DJ. The relationship between blood groups and disease. Blood 2010; 115: 4635-43.

16. Wilson AF, Elston RC, Siervogel RM, Tran LD. Linkage of a gene regulating dopamine- $\beta$-hydroxylase activity and the $\mathrm{ABO}$ blood group locus. Am J Hum Genet 1988; 42: 160-6.

17. Irvine DG, Miyashita H. Blood types in relation to depressions and schizophrenia: a preliminary report. Can Med Assoc J 1965 92: 551-4.

18. Parker JB, Theilie A, Spielberger CD. Frequency of blood types in a homogeneous group of manic-depressive patients. BJP 1961; 107: $936-42$
19. Tsuchimine S, Saruwatari J, Kaneda A, Yasui-Furukori N. ABO blood type and personality traits in healthy Japanese subjects. PLoS One 2015; 10: 1-10.

20. Kakathkar S, Srinivasan I, Setty J, Akhil P, Suting C, Nayana K. Correlation between A, B, and O blood group system and dental anxiety in children of age 6-12 years in East Bengaluru. J Int Clin Dent Res Organ 2020; 12: 127-31.

21. Alataş M. Kan grupları ve stres düzeyi arasindaki ilişkiler. Int J Innov Eng Appl 2018; 2: 50-2.

22. Beyazıt F, Pek E, Güngör AÇ, Gencer M, Unsal MA. Effect of maternal $\mathrm{ABO}$ blood type on birth weight and preeclampsia. Int J Reprod Contraception Obstet Gynecol 2017; 6: 2164.

23. Aghasadeghi F, Saadat M. Association between $\mathrm{ABO}$ and $\mathrm{Rh}$ blood groups and risk of preeclampsia: A case-control study from Iran. Open Access Maced J Med Sci 2017; 5: 173-6.

24.Sjöström K, Valentin L, Thelin T, Maršál K. Maternal anxiety in late pregnancy and fetal hemodynamics. Eur J Obstet Gynecol Reprod Biol 1997; 74: 149-55.

25. Andersson L, Sundström-Poromaa I, Wulff M, Åström M, Bixo M. Neonatal outcome following maternal antenatal depression and anxiety: A population-based study. Am J Epidemiol 2004; 159: 872-81. 